\title{
LA AUTOGESTION HABITACIONAL EN EL CHILE NEOLIBERAL Análisis de las practicas del Movimiento de Pobladores y Pobladoras en Lucha, MPL
}

\author{
Habitational self-management in the Neoliberal Chile
} Practices's Analysis MPL movement

\author{
Espinoza, Ural \\ Pontificia Universidad Católica de Chile - Instituto de Estudios Urbanos \\ udespinoza@uc.cl
}

\begin{abstract}
RESUMEN
La rearticulación de movimientos sociales territoriales en defensa de su hábitat urbano, por un lado, y la incorporación de conceptos como integración social dentro de la política de vivienda, por otro lado, ha visibilizado la crisis de acceso a una vivienda digna en un país que durante años se ha caracterizado por demostrar el alcance de su política habitacional. Las entrevistas a actores públicos demuestran que el invasivo modelo de producción habitacional ha presionado inclusive al MPL a reinventar sus prácticas de acción colectiva para acceder a la vivienda. La voluntad por cambiar el modus operandi dentro de la política, ha construido un movimiento anti sistémico a la chilena, en donde ser parte de la estructura institucional parece ser un requisito para tener voz.
\end{abstract}

Palabras clave: autogestión habitacional, política de vivienda, ciudad neoliberal, derecho a la ciudad. Bloque temático: teoría e historia de la ciudad.

\begin{abstract}
The rearticulation of territorial social movements in defense of their urban habitat, on the one hand, and the incorporation of concepts such as social integration within the housing policy, on the other hand, has made visible the crisis of access to decent housing in a country that for years it has been characterized by demonstrating the scope of its housing policy. Interviews with public actors show that the invasive model of housing production has pushed even the MPL to reinvent its collective action practices to access housing. This lack of willingness to change the modus operandi within politics has built an anti-systemic movement to the Chilean one, where being part of the institutional structure seems to be a requirement to have a voice.
\end{abstract}

Keywords: housing self-management, housing policy, neoliberal city, right to the city. Topic: theory and history of the city. 


\section{Introducción}

Pertenezco a una generación que creció escuchando anécdotas de cómo los procesos de autogestión tuvieron la oportunidad de cambiar el rumbo de un país. El impulso de la educación popular y la promoción de la cultura pertenecieron a la memoria de una nación que nunca fue. El progresismo de Nicaragua ilusionó a toda Latinoamérica, en un momento en donde las izquierdas del cono sur sufrían una derrota. Si bien, en aquel momento el Estado nicaragüense fue un ejemplo de organización popular en los años subsiguientes la centralización del poder, la desregulación de la economía y los nuevos acuerdos políticos detonaron, en una tarde de Abril, la crisis de legitimidad de los jóvenes ante el Estado.

Por tanto, reflexionar sobre los procesos de autogestión en términos habitacionales resulta urgente, en un momento en donde los urbanos espacios construidos son utilizados como mecanismos de lucro. Más aún en un país como Chile, en donde el aumento del precio de la vivienda, la diminución en la producción del parque habitacional, el deterioro de los conjuntos construidos en los 90 s y el incremento de los asentamientos espontáneos ha problematizado el acceso a la vivienda digna. En efecto, las demandas de los movimientos sociales en defensa de su hábitat urbano han visibilizado con más fuerza esta problemática en un país que durante años se ha caracterizado por el alcance de su política habitacional.

Sin embargo, la incorporación del término autogestión dentro de los marcos institucionales da cuenta de una intencionalidad por promover procesos de participación vinculante dentro de la gestión habitacional. A pesar de ello, su corta vigencia dentro del Decreto Supremo 491 tampoco garantizaba opciones reales para que los pobres urbanos siguieran residiendo en sus comunas de origen. En general, esta nueva voluntariedad por insertar conceptos trending dentro de la política habitacional ha construido un discurso capitalista compatible con todo el espectro político. Por tanto, hoy resulta más urgente cuestionarse si estas iniciativas conducen ¿hacia un nuevo paradigma de producción habitacional?, o en cambio sospechar ¿Cuáles son los verdaderos intereses movilizados por estas nuevas estrategias encubiertas?

A partir de ello, este articulo analiza las practicas del Movimiento de Pobladores en Lucha (MPL), las cuales se destacan como iniciativas pioneras en la historia contemporánea de acción colectiva en defensa de la vivienda digna. La consolidación de un discurso que levanta la autogestión habitacional como una de sus principales banderas de lucha conduce a la siguiente pregunta de investigación

\section{¿De qué manera construyen las prácticas de autogestión habitacional el Movimiento de} Pobladores en Lucha en un contexto institucional neoliberal?

\section{Objetivo General}

Analizar de qué manera la autogestión habitacional que moviliza el Movimiento de Pobladoras y Pobladores en Lucha se construye en un contexto de producción de vivienda masiva.

\section{Objetivos Específicos}

1. Describir el contexto actual de la política masiva de vivienda en Chile, referido a síntomas de agotamiento y a nuevas modalidades de acceso a la vivienda dentro del Decreto Supremo 49.

2. Describir el nacimiento y evolución del MPL, y su modelo de autogestión habitacional.

3. Identificar los espacios de acción del movimiento dentro del marco institucional actual.

4. Discutir la idea de autogestión habitacional en el Chile contemporáneo, a partir de las prácticas y estrategias del movimiento en un contexto de provisión masiva de vivienda en propiedad.

\footnotetext{
${ }^{1}$ El Fondo Solidario de Elección de vivienda o Decreto Supremo 49, se refiere a la herramienta legal utilizada para acceder a una vivienda sin deuda, destinado a las familias en situación de vulnerabilidad social.
} 


\section{Estado Actual}

Las nuevas iniciativas para acceder a la vivienda en Chile se inscriben bajo un modelo tripartito (Sociedad Civil-Estado-Mercado), el cual garantizó la disminución del déficit cuantitativo principalmente en la década de los 90’s. (ver Fig. 01). La producción en masa de vivienda en las periferias de la ciudad generó grandes manchas homogéneas residenciales. El continuo deterioro de la condición material y simbólica dentro de estos conjuntos habitacionales desembocó en el menoscabo de la calidad de vida de sus residentes (Ducci, 1997).

A

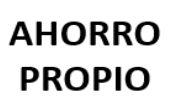

INDIVIDUO
B

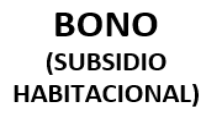

ESTADO
C

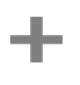

VIVIENDA

PRODUCTO

Fig. 01 Ecuación del Modelo Habitacional Chileno. Fuente: Elaboración Propia

La "nueva pobreza urbana" (Tironi, 2003) de "los con techo" (Rodríguez, y Sugranyes, 2004) y la falta de voluntad política por garantizar la vivienda digna como un derecho social ha conducido a diversos autores a concluir que el modelo subsidiario a partir del cual se basa la política habitacional "es ante todo un mecanismo de financiamiento de apoyo al sector empresarial inmobiliario y de la construcción" (Rodríguez, y Sugranyes, 2004:4). A pesar de que el sector privado y el Estado sostengan que el subsidio habitacional es un mecanismo destinado a la demanda, las evidencias indican que este es absorbido casi en su totalidad por los precios del suelo. (Brain, Cubillos, \& Sabatini, 2007).

Cuatro décadas después, la incorporación de nuevas modalidades de acceso a la vivienda ${ }^{2}$ dentro del Decreto Supremo 49 ha reflejado el eco de las demandas de los pobres urbanos dentro de la política habitacional. A partir de ello, la rearticulación de movimiento territoriales en defensa de su hábitat se ha visibilizado inclusive en Comunas de clase media alta como Ñuñoa y la Reina (ver Fig. 02 y Fig. 03). Estos movimientos utilizan estos nuevos espacios de participación ciudadana inscritos dentro de la institucionalidad chilena para instalarse como sujeto político desde el territorio. Esta participación activa de nuevos actores políticos en defensa de su hábitat urbano ha consolidado las prácticas de autogestión habitacional como plataforma de lucha por el derecho a la ciudad.

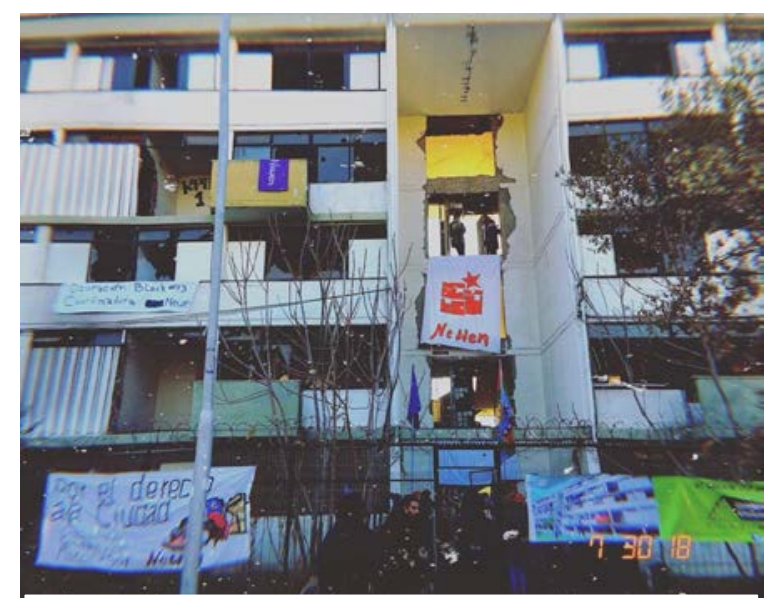

Fig. 02 Toma Block Villa Olímpica, Comuna de Nuñoa. Fuente: Coordinadora de comités de Vivienda Newen,

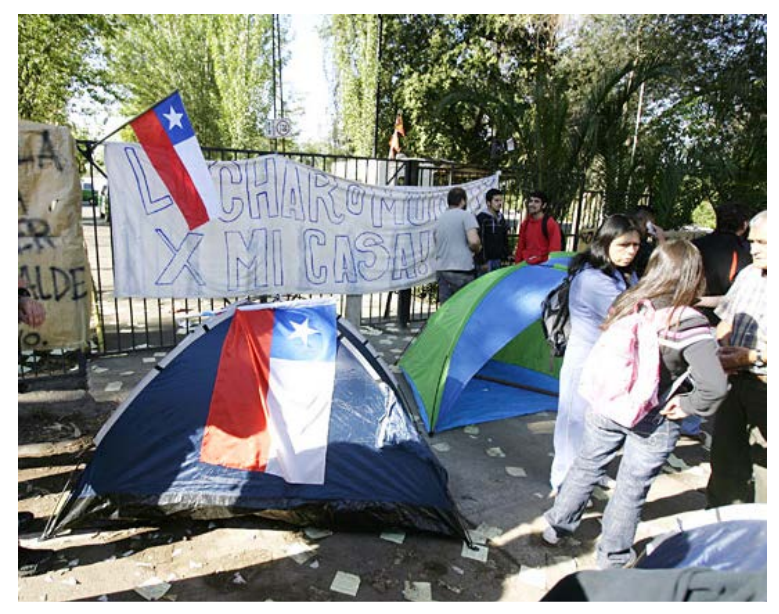

Fig 03 Toma de terreno Universidad de Chile, Comuna La Reina Fuente: Emol Nacional, 2011

\footnotetext{
${ }^{2}$ Decreto de autogestión 2014, Cooperativa de vivienda Nuke Mapu 2016.
} 


\section{Marco Teórico}

¿No es claro ya que la participación real y activa tiene un nombre? Ese nombre es autogestión. Lefebvre, 2017 $: 123$

En contra a los ideales iniciales de Lefebvre, la incorporación de conceptos como la participación ciudadana, gobernanza e integración social dentro de política habitacional han garantizado el fortalecimiento del modelo neoliberal a partir de la promoción de mecanismos de inclusión. (Miraftab, 2009; Ortiz, 2013). Por tanto, la manipulación de un concepto que originalmente tiene como objeto la emancipación, puede ser utilizado para el control y la cooptación ciudadana. (Giuseppe, 2011), inclusive por lo actores menos esperados.

El neoliberalismo, entendido como el modelo político, económico y cultural que implica la reformulación de relaciones entre el Estado, el mercado y la sociedad civil, ha debilitado las atribuciones del Estado por medio de la participación activa del individuo. Por tanto, los mecanismos políticos utilizados han conducido a los actores más radicales, a actuar entre la resistencia y la inclusión (Miraftab, 2009). De manera que "la autogestión al estilo neoliberal resulta en realidad una especie de máscara progresista en la que se esconden las condiciones de desigualdad que enfrentan los individuos responsabilizados de sí mismos, pero neutralizados en su capacidad de acción a un nivel social y político." (Ortiz, 2013:6).

Las contribuciones de Lefebvre (2017), también pueden ser comparadas con las de Turner (1976). En relación a la autoproducción del espacio, ambas conceptualizaciones teóricas desarrollan la importancia en el rol del sujeto para transformar su entorno socio-espacial (Bower, 2016). John Turner por su parte, conceptualiza los procesos de autogestión habitacional afirmando que

"las estructuras radiales y las tecnologías descentralizadas, esto es, los sistemas locales autogobernados, constituyen los únicos métodos y medios capaces de proporcionar bienes y servicios satisfactorios, " (Turner, 1977, p. 31).

El aporte más significativo de Turner es explícitamente espacial y político, teniendo como centro de su argumento la construcción de procesos autónomos. Dicha construcción solo es posible bajo dos condicionantes, estructuras radiales es decir la constante reflexión - acción (praxis) y tecnologías descentralizadas que aluden a la distribución del poder.

Ahora bien, la autonomía como concepto socio político a partir del cual se funda la autogestión, advierte la dialéctica entre el Estado y las multitudes. La dependencia entre Estado y multitudes no es perjudicial en si misma, lo perjudicial es la desproporcionada relación entre los actores presentes. (Turner, 1979) De manera que resulta esencial cuestionarse ¿Cuáles son las cuotas de poder de los actores involucrados dentro de los procesos de autogestión habitacional? ¿Cómo se articula la relación entre quien provee y quien decide? El autor insiste que estos procesos tienen su génesis en dos puntos: la capacidad de negociación (entre agencia y estructura) y la capacidad de administrar la libertad de acción por costos. (Turner, 1979)

De manera que, proclamar la autogestión dentro de los márgenes institucionales ha abierto el debate sobre los intereses que se ocultan detrás. El fuerte componente político que desencadenan estas prácticas ha conducido a incorporar "el derecho a la ciudad" dentro de su discurso. Harvey por su parte define el derecho a la ciudad como algo que transciende el derecho individual a acceder a los recursos urbanos, como

"un derecho común antes que individual, ya que esta transformación depende inevitablemente del ejercicio de un poder colectivo para remodelar los procesos de urbanización. La libertad de 
hacer y rehacer nuestras ciudades y a nosotros mismos es, uno de nuestros derechos humanos más preciosos, pero también uno de los más descuidados" (Harvey, 2008:23)

La búsqueda de reivindicar una lógica de "lo colectivo" también ha consolidado los postulados de Lefebvre dentro de las nuevas expresiones de acción colectiva. Por tanto, la búsqueda de "lo colectivo" con "lo político" dentro del discurso de las nuevas formas de autogestión habitacional ha encaminado a estos nuevos actores a poder cobijarse bajo esta misma consigna.

Por tanto, si las nuevas prácticas de autogestión se inscriben dentro de un modelo neoliberal ¿es justo despojarlas de su dimensión política en tanto no adviertan cambios estructurales? . Dentro de este contexto, en donde el neoliberalismo opera como proyecto político, económico y cultural, "la autogestión se releva como mecanismo al mismo tiempo que objeto, como fin y como medio de la transformación del espacio" (Link, 2015), siendo la demanda habitacional el catalizador por excelencia de los movimientos sociales actuales.

\section{Metodología}

-Enfoque metodológico: enfoque inductivo con paradigma interpretativo.

-Elección de estudio de caso: se precisó elegir entre las distintas organizaciones sociales emergentes dentro del país que se auto declaran como autogestionados. Movimientos como el UKAMAU, MPL y la Cooperativa Ñuke Mapu fueron revisados por la visibilidad que han tomado en el último periodo. A partir de ello, además de su antigüedad, el MPL fue elegido por haber complejizado su forma organizacional para materializar varios proyectos de vivienda dentro de la Comuna de Peñalolén. La propuesta organizacional al interior de la EaGIS, la vinculación a escala nacional por medio de la FENAPO y la creación del Partido Igualdad ha consolidado el movimiento a nivel regional y nacional.

-Recopilación de datos: se realizó una revisión de fuentes secundarias como documentos de tesis de grado y posgrado, documentos de la Corporación Poblar y revisión de sitios webs. En esa lógica se presenció de manera virtual o presencial eventos organizados por el movimiento (un foro de capacitación, mesa de discusión, una inauguración de un conjunto habitacional y una mesa de discusión con la Municipalidad), asimismo se co-diseñó, el seminario "La autogestión habitacional en el Chile Neoliberal: ¿Reminiscencias del Pasado o un nuevo futuro para la vivienda?" con el objeto de realizar un análisis cualitativo de contenido de discurso. Y a partir de ello, se elaboraron entrevistas semiestructuradas a un miembro de comité de vivienda MPL, un líder MPL, académicos - ex militantes MPL, representantes del Estado, y asistente técnico EGIS-EaGIS. 


\section{Contexto Histórico}

La emergencia de nuevos movimientos territoriales se consolida en torno a la figura del poblador como sujeto político, quien construye su racionalidad en base a la memoria del histórico movimiento de pobladores de los sesenta (Angelcos\&Pérez, 2017; Garcés, 2011). A partir de ello, se analiza las transformaciones de la autogestion habitacional en tres ciclos,

Primer ciclo (1950s-1973). Se destacan por una fuerte dialéctica entre el movimiento de pobladores y el Estado. Las tomas de terreno se transforman en la estrategia utilizada para ejercer presión sobre el Estado (Garcés, 2002: Cortés, 2014). A pesar de los esfuerzos que realizó el Estado por regularizar la ciudad por las necesidades de los pobres urbanos seguían sin respuestas efectivas. (Hidalgo, 2007). Por tanto, el poblador se destacaba por articular social y políticamente las demandas por la vivienda a través de la autoconstrucción.

Segundo ciclo (1973-1989). En medio de un régimen dictatorial, las demandas habitacionales pierden centralidad. Sin embargo, la autogestión se materializa en las prácticas de sobrevivencia, solidaridad y resistencia. El protagonismo de la iglesia católica fue reflejado por medio de la Vicaria de la Solidaridad, que se operó como el centro institucional de resistencia más importante en Chile (Soles, 2018).

El periodo entre 1989-1999. Se destaca por una atomización de las organizaciones sociales principalmente por las condiciones impuestas por la concertación y la masiva política habitacional.

Tercer ciclo (1999-actualidad). El último ciclo tiene como punto de partida la Toma de Peñalolén, en donde 1700 se toman el terreno de Miguel Nazur con el objeto de materializar sus demandas habitacionales. Este sería el primer antecedente contemporáneo a partir del cual se conforma el "Comité de allegados Lucha y vivienda" en el año 2003. (Mathivet\&Pulgar, 2011). (ver Fig. 04)

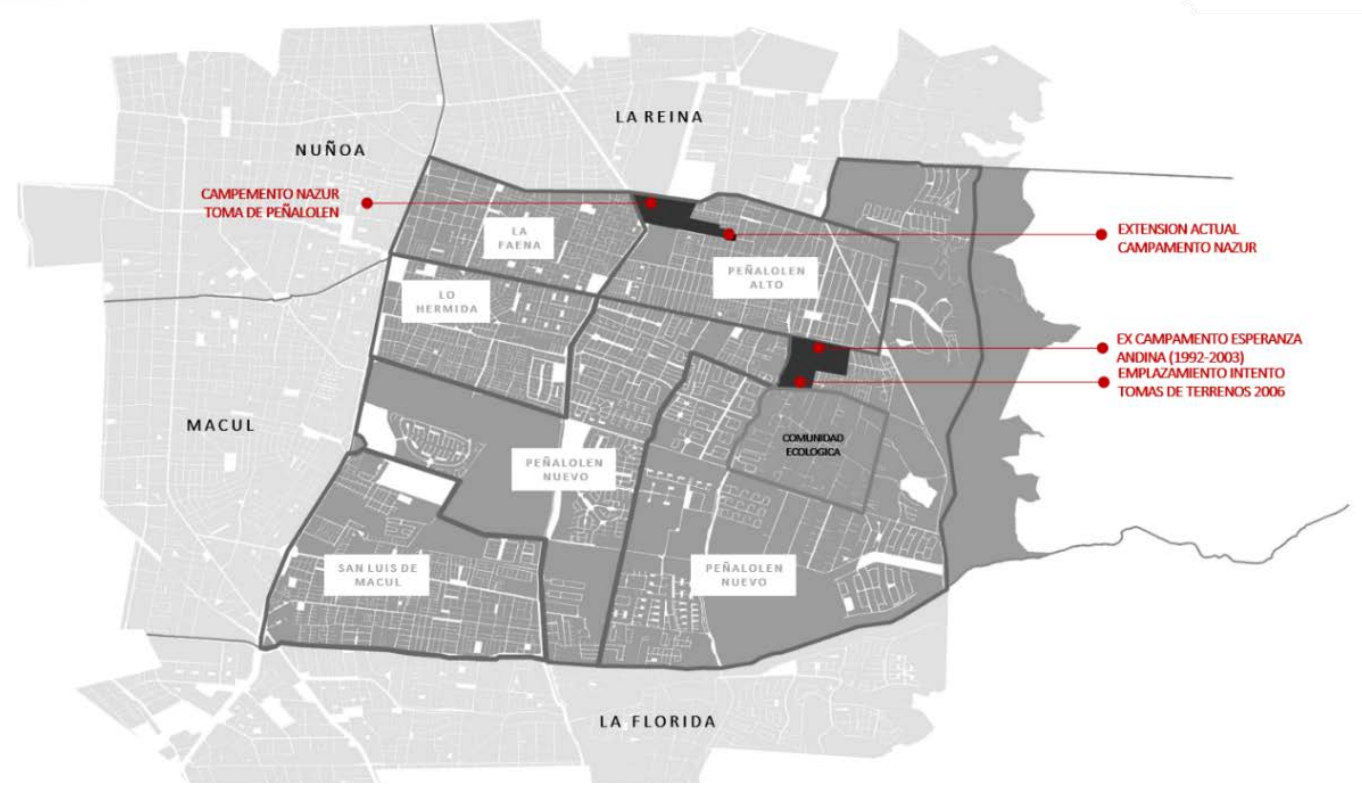

Fig. 04 Localización de Tomas, Comuna de Peñalolén. Fuente: Elaboración Propia en base a Renna (2010) 


\section{Movimiento de Pobladoras y Pobladores en Lucha}

Tras la desarticulación del campamento en el mismo año, el comité compuesto por 500 familias funda el MPL en el año 2006. A partir de este año, el movimiento instala el discurso de "retornar el papel histórico de los pobladores como constructores de ciudad" (Mathivet\&Pulgar, 2011:214). Es así como se han planteado cinco grandes objetivos (Renna, 2010):

-Conquistar el derecho a permanecer en la Comuna.

-Transformase en una fuerza productiva autónoma.

-Levantar estrategias autogestionarias de acción popular

-Ganar espacios de representación dentro de la institucionalidad política.

-Incidir en la planificación urbana de la comuna.

\subsection{La Entidad de Autogestión Habitacional (EaGIS)}

La EaGIS nace como respuesta contestataria a la EGIS o Entidades de gestión Inmobiliaria Social. Estas entidades de carácter privado o público, personas naturales o jurídicas, con o sin fines de lucro, están encargadas de dar asesoría especializada a los beneficiarios durante el proceso de postulación a programas del Ministerio de Vivienda y Urbanismo (MINVU). Las EGIS son fiscalizadas por las SEREMI de cada región y entre sus funciones se encuentra: organizar la demanda, asesorar la adquisición de viviendas construidas, diseñar y elaborar proyectos de arquitectura e ingeniería, diseñar y ejecutar un Plan de Habilitación Social, además de la contratación de obra (Imilan, 2016). La conformación de un EaGIS administrada por los pobladores ha cuestionado el rol del tercer sector dentro de la ecuación habitacional.

Según Kombluck, esto les permite una ganancia del 20-30\% del presupuesto destinados a la vivienda. Por tanto, la administración de recursos del estado también se configura como una expresión de autogestión, así lo explica Garrido "en estos largos 12 años que cumplimos, hemos desarrollado varias [forma de autogestión] (...) y una de esas es la administración de los fondos públicos."

La lógica organizacional de la EaGIS se funda en las asambleas, las cuales se dividen en tres áreas de acción: las asambleas de dirigentes, la asamblea de vivienda y la asamblea de profesionales EaGIS. La asamblea de dirigentes funciona como puente entre los dirigentes de la EaGIS y los dirigentes de otros aparatos dentro del movimiento, con el objeto de deliberar en conjunto lineamientos y disposiciones. Por su parte, la asamblea de vivienda, reúne a todos los interesados en postular a una vivienda organizados en los distintos comités, dentro de los cuales se deliberan asuntos no necesariamente relacionados sólo al tema de la vivienda. Y finalmente está la asamblea de profesionales, la cual inicialmente se creó para generar el debate entre estos actores en torno la gestión de la vivienda. Sin embargo, posteriormente se integraron representantes de las asambleas de vivienda dentro de este espacio. (Andrade, 2014). Según Meza (2016) las asambleas se localizan en el centro de su modelo de gestión. (ver Fig 05 y Fig. 06) 


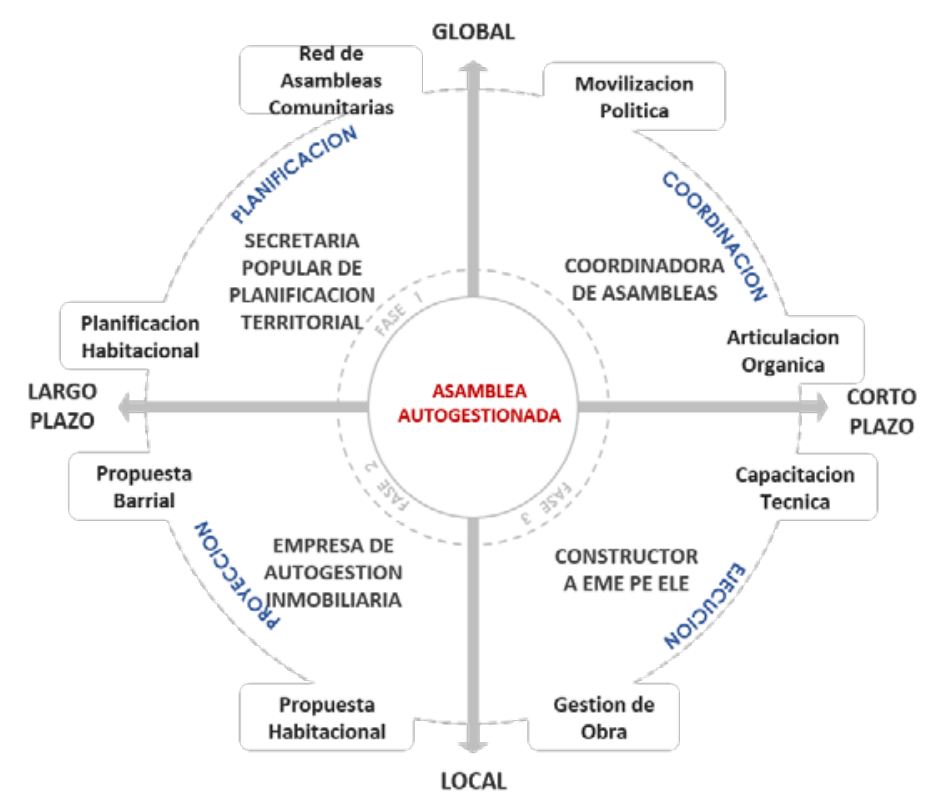

Fig. 05 Modelo de Gestión Habitacional Movimiento de Pobladoras y Pobladores en Lucha. Fuente: Adaptación del modelo de Gestión habitacional elaborado por Daniel Meza Corvalán, Nuevas Prácticas socio-espaciales de autogestión en Santiago de Chile: El acceso a la vivienda y el poder instituyente. Constested Cites. 2017

\subsection{La Corporación Educacional Poblar}

Poblar también contribuyó a ejercer de forma integral el concepto de autogestión dentro de la organización. Esta corporación, además de promover espacios de formación como jardines infantiles, foros, encuentros y escuelas para adulto mayor, dirigió siete diplomados de formación política para sus dirigentes y externos. De esta forma, la autoformación del movimiento en términos individuales y colectivos es una de las premisas más importantes para consolidarse como una organización social con capacidad de gestión. 


\section{SIIU}

barcelona|santiago de chile junio 2019

DOl: $10.5821 /$ SIIU.6782

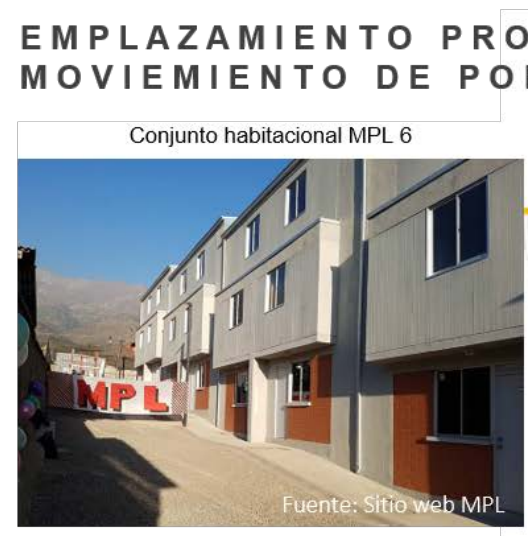

Conjunto Habitacional MPL2

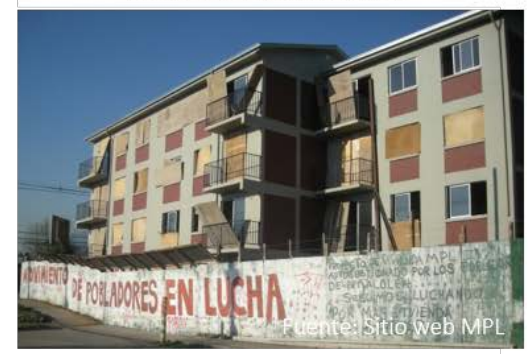

\section{YECTOS}

MOVIEMIENTO DE POBLADORAS YPOBLADORESEN LUCHA
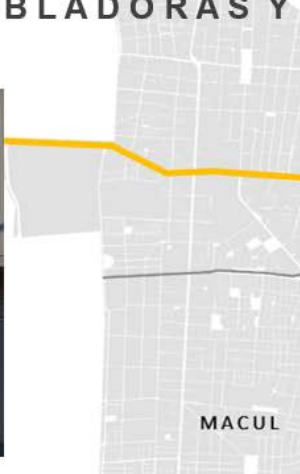


\section{Las estrategias de autogestión habitacional}

La consolidación de los aparatos de gestión antes descritos ha conducido al movimiento a materializar proyectos modelos de integración urbana dentro de la ciudad de Santiago de Chile. Parte de sus estrategias territoriales son:

El arraigo como demanda territorial.: Además de estimular el continuo mejoramiento en la calidad de vida de los pobres urbanos, el arraigo territorial consolida la idea de la construcción de un proyecto colectivo que había sido arrebatado durante los años 90’s.

El subsidio a la localización como mecanismo para materializar la demanda territorial.: El subsidio a la localización opera como el instrumento que hace posible la construcción de conjuntos habitacionales con acceso a servicios y equipamientos públicos de calidad. Si bien el subsidio ha dado respuesta a corto plazo, investigaciones empíricas en países como Brasil demuestran que su implementación reproduce la segregación socio-espacial dentro de las ciudades. (Stiphany y Ward, 2019). Por tanto, mientras no se implemente una política de suelo por medio de la cual se promuevan otros mecanismos para acceder a un terreno bien localizado, los pobladores residirán en sus comunas de origen a costa del incentivo de la especulación.

La autogestión habitacional como mecanismo histórico de construcción social del hábitat.: El carácter histórico de las prácticas de autogestión habitacional es reflejado en las historias de vida de las y los dirigentes más importantes del movimiento.

La autogestión habitacional como medio y fin.: El MPL construye el concepto autogestión habitacional en base al discurso de la vida digna. Para el movimiento, la búsqueda de la vida digna se proyecta como un horizonte que se alcanza en la cotidianidad con cada acción, cada lucha, cada trabajo, cada proyecto (Andrade, 2014). De esta manera la autogestión habitacional se convierte en un medio y un fin (Link,2015).

\section{Entre la inclusión y la resistencia.}

Las dos dimensiones a partir de las cuales se componen las prácticas de autogestión, la política y la económica, son explicadas alrededor de dos hitos importantes dentro de la historia contemporánea del MPL, a criterio de la autora. En términos políticos, la fundación del Partido Igualdad como herramienta para movilizar las demandas del movimiento visibiliza el comportamiento estratégico del MPL dentro de contextos socio-políticos favorables. Con el objeto de posicionarse en el gobierno central y en el comunal. (ver Fig. 07)

Por otro lado, en lo económico se destaca la inserción del concepto de autogestión habitacional dentro de las políticas públicas en el Articulo 68, dentro del DS 49. Si bien este decreto tampoco garantizó procesos verdaderos de autogestión, el avance cualitativo tuvo que ver con visibilizar, en términos institucionales, la capacidad de agencia por parte de los pobres urbanos. Así lo expone Natalia Garrido,

"(E)l artículo 68, hablaba de autogestión. De ahí, no salió mucho, la bajada no fue lo que nosotros nos hubiese gustado. (...) Llegó el gobierno de la nueva mayoría (...), borro el artículo. No pudimos implementarlo" (Natalia Garrido, líder MPL)

SI bien esta iniciativa fue impulsada por un gobierno de derecha, la perversión de estas acciones estuvo dadas en impulsar a las organizaciones sociales en convertirse en una empresa patrocinante. Y por tanto, introducirlas dentro de una competencia entre actores dispares (empresa privada - organizaciones sociales), en donde la falta de financiamiento fue uno de los trampas más importantes. Por tanto, en la actualidad la autogestión solo tendrá densidad en la medida en que esta se conceptualice como un proceso y en la actualidad, como un proceso de construcción política. Así lo describe Mauricio "en términos neoliberales rentabiliza más la movilización que la autogestión". 
A pesar de los esfuerzos por incorporar este tema dentro de la institucionalidad, antes de operacionalizar es preciso comprender que el origen de la autogestión se fundamenta en estimular herramientas antes que productos. En términos económicos, la clave está en abrir el espectro de posibilidades, en donde la vivienda sin deuda y llave en mano no sea la única opción para adquirir la vivienda de forma autogestionada. En este sentido, explorar otros marcos normativos en donde el DS 49 no se la única opción. Asimismo, garantizar la capacidad de agencia de otras figuras organizativas, en donde la cooperativa tampoco resulte ser la única alternativa.

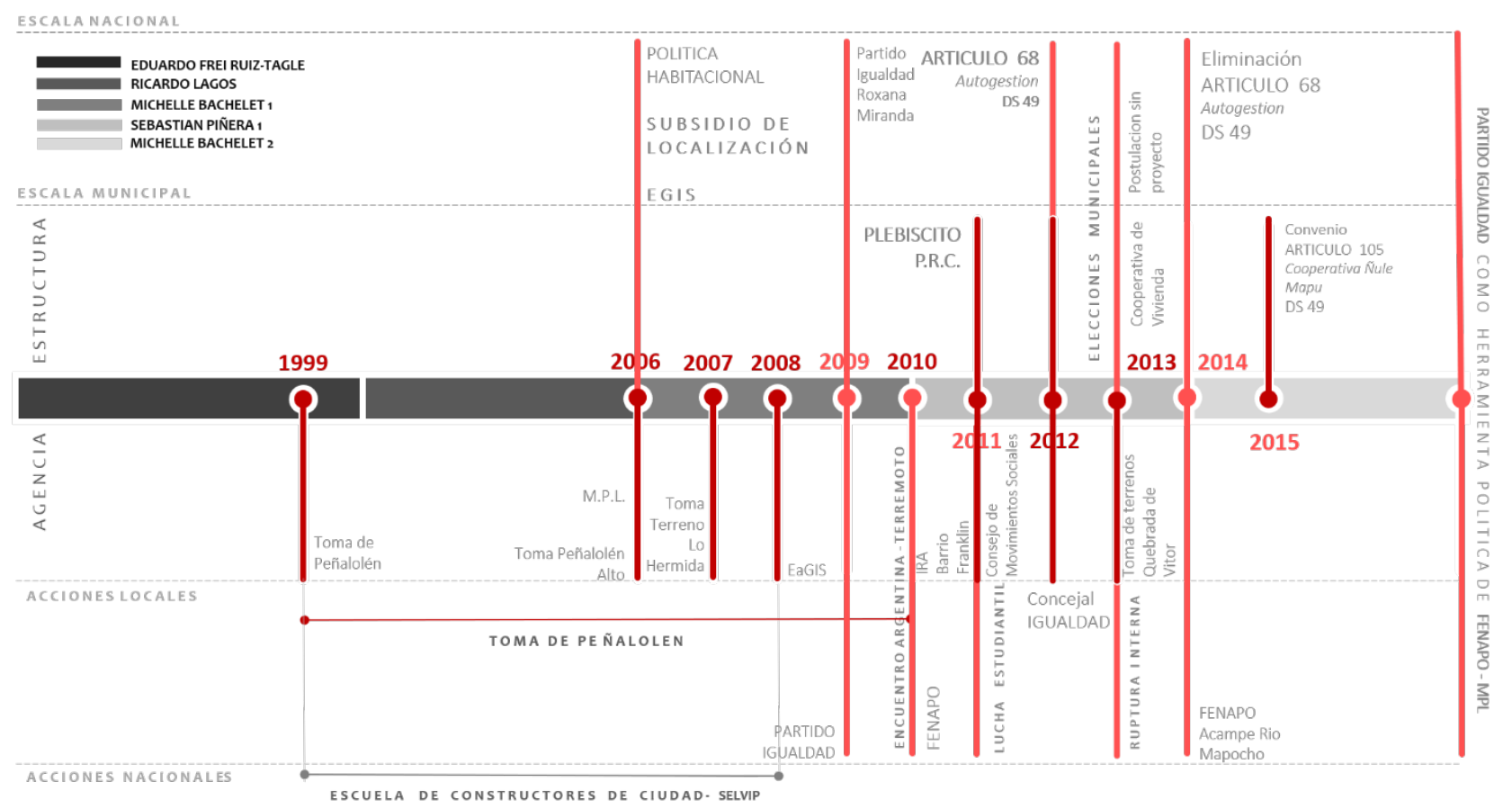

Fig. 07 Interacción Política habitacional vs MPL. Fuente: Elaboración Propia en base a Anglecos, Aravena, Meza y González

\section{Conclusiones}

A partir de lo anterior se puede concluir que las prácticas de autogestión habitacional por parte del MPL se han visto modificadas en tanto se relacionen con la actual política habitacional. Sin la intensión de tomar posturas duales ante los nuevos matices de este fenómeno, es preciso declarar que el concepto de la autogestión se difumina (o neoliberaliza) dentro de un contexto de una gobernanza metropolitana, donde las demandas de la sociedad civil son cada vez más diversas y complejas.

Por un lado, la creación del partido Igualdad da prueba que, al convertirse en el aparato político institucional de la FENAPO, han actuado como entidades que movilizan conjuntamente las demandas del MPL. Este paralelismo entre instituciones, ha garantizado el crecimiento y consolidación de un movimiento anti sistémico a la chilena, en donde ser parte de la estructura institucional parece ser un requisito para tener voz. Así pues, mientras otras modalidades de acción política sean inválidas para posicionarse como sujeto político dentro de la ciudad, los movimientos sociales replicaran prácticas políticas tradicionales para validarse ante el otro, en detrimento de su propia naturaleza orgánica.

De igual forma, la eliminación del artículo 68 dentro del DS49, que integró de forma laxa la posibilidad de implementar prácticas de autogestión habitacional por colectivos organizados, demuestra que no existe una voluntad para cambiar el modus operandi de la actual política habitacional. Con todo, se advierte que el éxito 
de la política habitacional ha sido de tal magnitud que inclusive los movimientos anti-sistémicos han tenido que utilizar los espacios de participación diseñados en beneficio del mercado. En donde "humanizar el capitalismo" parece ser la única opción de intervención. Así pues, en contra de sus ideales, movimientos como el MPL han adoptar mecanismos tradicionales de gestión habitacional para ser escuchados dentro de la toma de decisiones. Esto ha posibilitado la consolidación de un aparato de producción habitacional a la chilena, el cual ha modificado los estándares de calidad de la vivienda no sólo al adquirirla (durante) sino al gestionarla (antes).

Si bien, aparentemente las acciones del MPL reproducen mecanismos tradicionales para acceder a la vivienda como la creación de un partido político para movilizar sus demandas y la gestión de subsidios habitacionales para materializar los conjuntos habitacionales, ¿podrían determinarse como prácticas tradicionales de gestión habitacional? ¿sus prácticas se desvinculan del fenómeno de autogestión? Para ello, es necesario advertir que la génesis de la autogestión esta en la construcción horizontal de las relaciones de poder. De manera que, en tanto los pobladores gestionen sus viviendas negociando directamente con las instituciones del Estado sin necesidad de intermediarios, las bases para construir este fenómeno estarán dadas.

El MPL y otros movimientos han intentado de abrir el espectro de las demandas de la vivienda digna por medio de la instalación del discurso de la vida digna, lo cual ha conducido a que la autogestión no se agote en la construcción. En este sentido, lo material - la vivienda ya no adquiere centralidad, y por lo tanto su gestión material, es decir, la construcción (o autoconstrucción). En cambio, la autogestión habitacional hoy responde a esta acción colectiva para resolver los problemas de vivienda de forma diferente. Por lo tanto, si ya se advertía una difuminación entre las dimensión política y económica dentro de los procesos de autogestión, lo anterior declara una relevancia de lo político por sobre lo económico. Así pues, la autogestión habitacional opera como una plataforma de acción política que estimula la lucha por el derecho a la ciudad, por medio de la generación de un proyecto colectivo.

\section{BIBLIOGRAFÍA}

ANDRADE, J. (2014) Pobladores y Autogestión. Sistematización de la Entidad de Auto-Gestión Inmobiliaria Social del Movimiento de Pobladores en Lucha (Tesis para optar al título de sociólogo). Universidad de Chile, Santiago de Chile.

ANGELCOS, N., \& PÉREZ, M. (2017). De la "desaparición" a la reemergencia: Continuidades y rupturas del movimiento de pobladores en Chile. Latin American Research Review, 52(1). doi: 10.25222/larr.39

BOWER, R. (2016). Who decides and who provides? The Anarchistic Housing Practices of John Turner as Realizationns of Henri Lefebvre's Autogestive Space. Alternatives: Global, Local, Political , 83-97.

BRAIN, CUBILLOS \& SABATINI (2007). Integración Social urbana en la nueva política habitacional. Pontificia Universidad Católica de Chile

CASTELLS, M. (1973). Movimiento de pobladores y lucha de clases en Chile. EURE 3(7): 9-35. Santiago de Chile.

CORTÉS, A. (2014). El movimiento de pobladores chilenos y la población La Victoria: Ejemplaridad, movimientos sociales y el derecho a la ciudad. EURE 40(119): 239-260. DOI: https://doi.org/10.4067/ S025071612014000100011

DECRETO SUPREMO 49 (2012). Diario oficial de la República de Chile, Santiago de Chile, 26 de Abril de 2012.

DUCCI, M. (1997). Chile: El lado obscuro de una política de vivienda exitosa. EURE23(69): 99-115

Garcés, M. (2002). Tomando su sitio. Santiago: LOM Ediciones 
Ibid. (2011). Movimientos Sociales e Izquierda en América Latina. Nuevas estrategias y nuevos movimientos. MPL/Corporación Poblar (Ed.). Latinoamericamente. P. 19-32. Santiago de Chile. Quimantú.

GIUSEPPE, C. (2011) ¿Una nueva alianza para la ciudad? Oportunidades y desafíos de la globalización del movimiento por el derecho a la ciudad. En C. \& Sugranyes, A. (Ed) Ciudad para todos. Por el derecho a la ciudad, propuestas y experiencias. P.105-118. Santiago de Chile.

HARVEY, D. (2008). The right to the City. New Left Review, 53 (September-October 2008). 23-40

HIDALGO, R. (2007). Cien años de política de vivienda social, cien años de expulsión de los pobres a la periferia de Santiago. En 1906/2006: Cien años de política de vivienda en Chile, editado por M. J. Castillo y Rodrigo Hidalgo, 51-63. Santiago: Universidad Andrés Bello.

IMILAN, W. A. (2016). Politicas y luchas por la vivienda en Chile: El camino neoliberal. Contested Cities

JARAMILLO, S. (2012). Urbanizacio informal: diagnosticos y politicas. Una revision al debate latinoamericano para pensar lineas de accion actuales. Centro de Estudios en Desarrollo Economico, CEDE, 33-83

LEFEBVRE, HENRY (2017). El derecho a la Ciudad. Capitan Swing. Madrid, España.

LINK, F. (2015). El derecho a la ciudad ¿Un programa de acción política? De Mattos \& Link. (Ed). Lefebvre revisitado: Capitalismo, vida cotidiana y el derecho a la ciudad. P.273-288. Santiago de Chile

MATHIVET, C. \& PULGAR, C. (2011). El Movimiento de Pobladores en Lucha: Los habitantes construyen un lugar para vivir en Santiago de Chile. Mathivet, C. \& Sugranyes, A. (Ed) Ciudad para todos. Por el derecho a la ciudad, propuestas y experiencias. P.211-232. Santiago de Chile.

MEZA, D. (2016) (Re)apropiaço da técnica (e do espaço) na autogestao habitacional: practicas espaciais na construçao de um modelo de promoçao de moradia por movimientos sociais no Chile. O caso do Movimiento de Pobladores en Lucha. (Dissertaçao de Mestrado para a obtençao do titulo Mestre ao Programa de PosGraduaçao em Geografia) Universidade Federal do Rio de Janeiro, Rio de Janeiro.

MIRAFTAB, F. (2009) Insurgent Planning: Situating Radical Planning in the Global South. . Planning Theory 8(1):32-50. The final, definitive version is available at http://online.sagepub.com

ORTIZ, GUADALUPE (2013) ¿Neoliberalismo autogestivo? La Cultura de Autogestión para el Desarrollo como herramienta analítica. Contextualizaciones Latinoamericanos No 9.

PRADILLA, E. (1977). Capital, Estado y vivienda en Latinoamérica. México: Fontamara.

RODRÍGUEZ, ALFREDO; SUGRANYES, ANA (editores) Los con techo. Un desafío para la política de vivienda social Santiago de Chile: Ediciones SUR, 2004 Obtenido desde: http://www.sitiosur.cl/r.php?id=81. Rodríguez, Di Virgilio. 2011. El caleidoscopio de las políticas territoriales. Prometeo. Bs As

SOLES, DIANE (2018). Reconfigurando lo público y lo privado en el Santiago de Pinochet. Un análisis de Género. En MONTEALEGRE PIA y ROZAS-KRAUSE VALENTINA (comps.) Disputar la ciudad (43-58). Santiago de Chile: Editorial Bifurcaciones.

TIRONI, MANUEL. (2003). Nueva pobreza urbana: Vivienda y capital social en Santiago de Chile, 1985-2001. Santiago: Universidad de Chile, PREDES/RILGarcés, 2011

TURNER, J. (1979). Vivienda: Todo el poder para el usuario. Madrid: H. Blume Ediciones.

Ibid, (1976) Housing by People: Towards Autonomy in Building Environments, Ideas in progress. London, Marion Boyars 